\title{
O alinhamento entre os níveis da Gramática Discursivo-Funcional em orações introduzidas por pero no espanhol
}

DOI: http://dx.doi.org/10.21165/el.v50i3.2977

\section{Talita Storti Garcia' \\ Carolina da Costa Pedro}

Resumo: A proposta deste trabalho é averiguar o alinhamento entre os níveis das orações introduzidas por pero em dados do espanhol peninsular falado, sob a perspectiva da Gramática Discursivo-Funcional de Hengeveld e Mackenzie (2008). O juntor pero é concebido na literatura da língua espanhola como conjunção coordenativa adversativa, equivalente a mas do português, ou a but do inglês. Para Hengeveld e Mackenzie (2009), o chamado alinhamento se refere ao mapeamento entre os Níveis Interpessoal, Representacional e Morfossintático da gramática. Os resultados mostram que contextos oracionais introduzidos por pero tendem a se estabelecer nas camadas mais altas do Nível Interpessoal. No Nível Morfossintático, observamos Orações que caracterizam o processo da coordenação. O universo de investigação é embasado no córpus PRESEEA (Proyecto para el Estudio Sociolinguístico del Español de España y de América).

Palavras-chave: pero; coordenação adversativa; Gramática Discursivo-Funcional; espanhol; alinhamento.

\footnotetext{
1 Universidade Estadual Paulista "Júlio de Mesquita Filho" (UNESP), São José do Rio Preto, São Paulo, Brasil; talita.garcia@unesp.br; https://orcid.org/0000-0001-8695-6086

2 Universidade Estadual Paulista "Júlio de Mesquita Filho" (UNESP), São José do Rio Preto, São Paulo, Brasil; costa.pedro@unesp.br; https://orcid.org/0000-0003-0130-966X
} 


\section{Alignment in Functional Discourse-Grammar in sentences introduced by pero in Spanish}

Abstract: This study proposes to investigate the alignment between the levels of clauses introduced by pero in peninsular Spanish spoken data, from the perspective of Functional Discourse Grammar (HENGEVELD; MACKENZIE, 2008). Pero is conceived in the literature of the Spanish language as an adversative coordinative conjunction, equivalent to the Portuguese mas, or the English but. According to Hengeveld and Mackenzie (2009), the so-called alignment refers to the mapping between the Interpersonal, Representational, and Morphosyntactic levels of the grammar. The results show that clausal contexts introduced by pero tend to establish themselves in the upper layers of the Interpersonal Level. At the Morphosyntactic Level, in turn, we observe Clauses that characterize the coordination process. The research universe is based on the PRESEEA (Project for the Sociolinguistic Study of Spanish from Spain and America).

Keywords: pero; adversative coordination; Functional Discourse Grammar; Spanish; alignment.

\section{Considerações iniciais}

Neste artigo, analisamos o alinhamento interpessoal, representacional e morfossintático das orações introduzidas por pero, no espanhol peninsular falado, sob a perspectiva da Gramática Discursivo-Funcional de Hengeveld e Mackenzie (2008).

De acordo com a Nueva Gramática de la Lengua Española - doravante NGLE (2009), pero é o juntor prototípico para assinalar adversidade no espanhol. Para Gili Gaya (2002, p. 281), as orações adversativas apesentam juízos de qualidade lógica diferentes, um afırmativo e outro negativo, como mostra (1):

1. Odiaba a su jefe, pero sabía disimular. (GILI GAYA, 2002, p. 281)

[Odiava seu chefe, mas sabia disfarçar]

Segundo Gili Gaya (2002), em (1), o segundo elemento sabía dimisular se opõe ao conteúdo da oração anterior odiaba a su jefe, já que, ao ouvir o falante dizendo que alguém odeia seu chefe, o ouvinte pressupõe que o ódio é explícito e que eles não se dão bem. No entanto, ao acrescentar a oração adversativa, diz que sabia dissimular, ou seja, fingia que gostava do chefe e, provavelmente, mantinham uma relação aparentemente amistosa.

Além do sentido adversativo, Gili Gaya admite que pero pode introduzir outro tipo de construção, quando ocorre em um único turno e apresenta uma dependência apenas pragmática, como em (2): 
2. Pero ¿cómo lo has sabido? (GILI GAYA, 2002, p. 282)

[Mas como você soube?]

Segundo a Nueva Gramática de la Lengua Española (2010), nesses casos, ainda há uma interpretação adversativa, mas uma parte da informação necessária para estabelecer seu significado precisa ser resgatada a partir da situação prévia, como demonstra (2), em que o falante pergunta ao interlocutor como ele soube daquela notícia que foi mencionada antes.

Para Hengeveld e Mackenzie (2008), as estruturas introduzidas por but ['pero'] constituem Concessão interpessoal, uma relação entre dois Atos Discursivos em que um é Nuclear, e o outro, Subsidiário. Para os autores, trata-se de uma estratégia do falante para alcançar seus objetivos na conversação. Eles reconhecem, no entanto, a atuação desse juntor em textos narrativos, em que but ['pero'] é usado pelo falante para fazer digressões ou acrescentar o que julga necessário na conversação.

Como se pode observar, consideramos, neste artigo, dois principais usos de pero no espanhol, quando apresenta uma relação de oposição entre dois membros oracionais, encaixando-se no esquema A pero B (cf. FLAMENCO GARCIA, 1999; DIK, 1997), e quando atua na organização do discurso, caso também reconhecido por Gili Gaya e por Hengeveld e Mackenzie. As ocorrências em que os elementos $A$ e $B$ constituem Sintagmas ou não se organizam em torno de um predicado não foram consideradas a fim de delimitar o objeto da investigação.

A partir desses usos, pretendemos investigar as motivações funcionais de uso de pero quando introduz estruturas oracionais no espanhol falado a fim de averiguar o alinhamento entre os níveis propostos pelo modelo da Gramática Discursivo-Funcional de Hengeveld e Mackenzie (2008).

Alinhamento é definido por Hengeveld e Mackenzie (2009) como o termo que é usado para designar o mapeamento de unidades pragmáticas e semânticas em unidades morfossintáticas. O primeiro tipo de alinhamento reconhecido pelos autores éo alinhamento interpessoal, que ocorre a partir da organização morfossintática e reflete na organização do Nível Interpessoal no que diz respeito às funções pragmáticas (Tópico, Foco, etc.) e às propriedades referenciais (identificabilidade, especificidade, etc.); o segundo tipo é o alinhamento representacional, quando a organização morfossintática reflete na organização do Nível Representacional no que diz respeito às funções semânticas (Ator, Paciente, etc.) e à designação (oposição animado/inanimado, pessoa gramatical, etc.); por fim, o alinhamento morfossintático exibe sua própria organização e "diz respeito quer às já mencionadas funções sintáticas (Sujeito, Objeto) quer à complexidade dos constituintes" (HENGEVELD; MACKENZIE, 2009, p. 186). 
Partindo do princípio de que todos esses níveis estão hierarquicamente organizados em camadas, a organização do Nível Morfossintático reflete a organização dos níveis Interpessoal e Representacional, respectivamente, em termos de funções pragmáticas e de funções semânticas. Os quatro níveis serão tratados na seção que segue.

\section{A Gramática Discursivo-Funcional}

A Gramática Discursivo-Funcional (doravante GDF), modelo proposto por Hengeveld e Mackenzie (2008), apresenta uma organização top down (descendente), que parte da intenção do falante e se desenvolve até a articulação, e apresenta natureza tipológica, que propõe sua aplicação em qualquer língua.

A GDF apresenta um Componente Gramatical e três Componentes não-Gramaticais: o Conceitual, o Contextual e o de Saída. Esses três últimos interagem com o Componente Gramatical, como é possível observar na Figura (1) a seguir:

Figura 1. Os componentes da Gramática Discursivo-Funcional

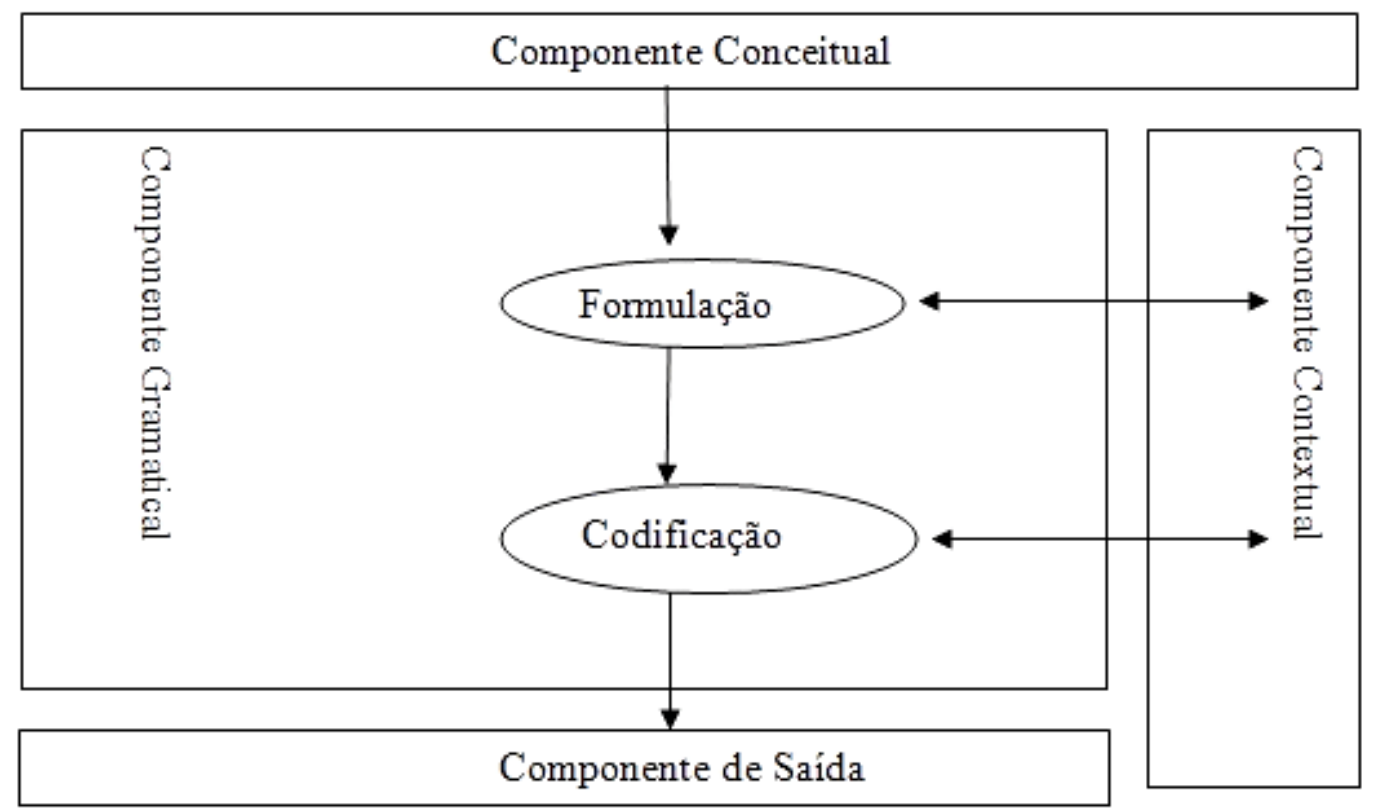

Fonte: adaptado de Hengeveld e Mackenzie (2008, p. 6)

O primeiro componente, o Conceitual, é aquele que, segundo Keizer (2015) contém as informações pré-linguísticas relevantes para a análise e é considerado como a força motriz por trás da Gramática. O Componente Contextual, por sua vez, corresponde à descrição do conteúdo, isto é, contém informações não linguísticas sobre o contexto discursivo imediato que afeta a forma de um enunciado linguístico. Por fim, o componente de saída, por sua vez, transforma a saída do componente gramatical em sinais acústicos ou ortográficos. 
A GDF é o Componente Gramatical de um modelo tipológico de interação verbal. Como observado na Figura 1, esse Componente interage com os componentes não gramaticais (Componente Conceitual, Componente de Saída e Componente Contextual) por meio das operações de Formulação e de Codificação. De acordo com Hengeveld e Mackenzie (2008), a Formulação diz respeito às regras que determinam as representações semânticas e pragmáticas em uma língua, enquanto a Codificação diz respeito às regras que convertem essas representações semânticas e pragmáticas em representações morfossintáticas e fonológicas. Desse modo, a Gramática Discursivo-Funcional propõe que tanto a Formulação como a Codificação são processos específicos de cada língua.

Essa teoria diferencia níveis de organização linguística: o Interpessoal (relacionado à pragmática), o Representacional (relacionado à semântica), o Morfossintático (relacionado à morfossintaxe) e o Fonológico (relacionado à fonologia), sendo todos eles de natureza puramente linguística. Para melhor ilustrar a representação dos níveis e camadas do modelo teórico, apresentamos, na figura (2), a arquitetura da Gramática Discursivo-Funcional:

Figura 2. Organização geral da Gramática Discursivo-Funcional

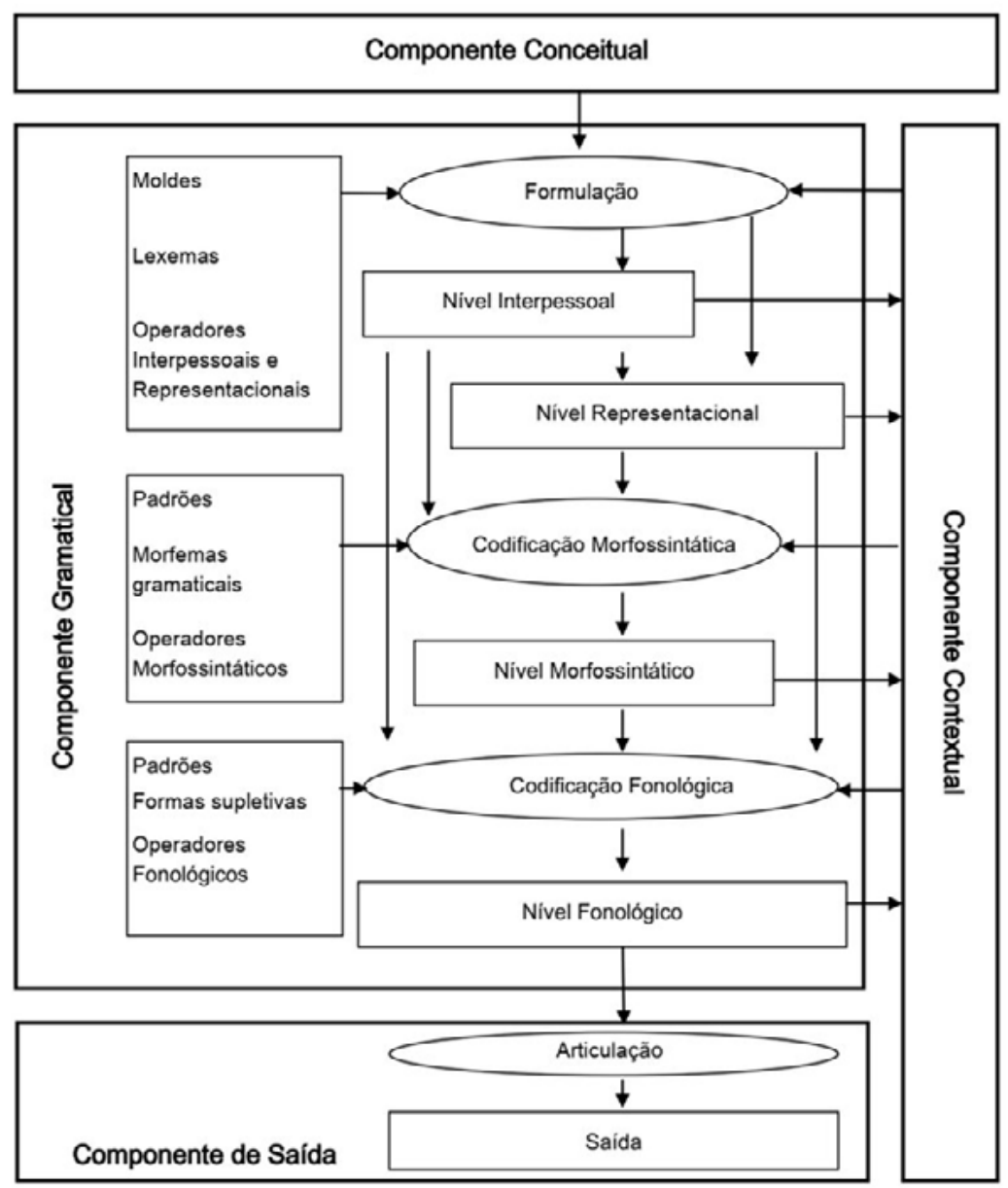

Fonte: Adaptado de Hengeveld e Mackenzie (2008, p. 13) 
Cada nível é organizado de distintas maneiras, mas todos são hierarquicamente ordenados em camadas. Portanto, a organização do Nível Morfossintático reflete a organização dos níveis Interpessoal e Representacional, respectivamente, em termos de funções pragmáticas e de funções semânticas.

O Nível Interpessoal (NI) apresenta o Movimento (M) como sua maior unidade. Em termos de estatuto interpessoal, o Movimento é definido como uma contribuição autônoma para a interação em desenvolvimento. O que o caracteriza é a possibilidade de ser ou desencadear uma reação, tendo assim um efeito perlocutório (HENGEVELD; MACKENZIE, 2008). O Movimento pode ser composto por apenas um ou mais Atos Discursivos.

O Nível Interpessoal, que trata das relações entre falante e ouvinte, apresenta o Movimento (M) como sua maior unidade. O Movimento, que pode ser composto por apenas um ou mais Atos Discursivos (A) combinados entre si, é definido como uma contribuição autônoma para a interação em desenvolvimento. Em uma interação, cada participante tem um objetivo em mente e o Falante moldará seu discurso para obter o seu propósito comunicativo.

O Ato Discursivo é a unidade básica de análise do modelo e é sempre parte de um Movimento. São exemplos de Atos Discursivos as frases conversacionais, como Parabéns! e Boa viagem!, as respostas em situação de interação como: A: Onde ela mora? B: Em São Paulo; e, por fım, vocativos, como Doutor! Cada Ato Discursivo contém uma llocução $\left(F_{1}\right)$, que especifica uma relação entre seus Participantes (P), o Falante (Speaker) e o Ouvinte (Addressee), e um Conteúdo Comunicado (C).

A relação entre os Atos pode ser de equipolência ou de dependência, havendo, nesse caso, um Ato Nuclear e um Subsidiário que apresenta uma função retórica (estratégias de que dispõem os falantes para alcançarem seus objetivos na comunicação). A última camada deste nível é o Conteúdo Comunicado que, segundo Hengeveld e Mackenzie (2008), contém o que o falante deseja evocar em sua comunicação.

O Conteúdo Comunicado (C) corresponde à totalidade do que o Falante deseja evocar na sua comunicação com o Destinatário e contém um número variável de Subatos Atributivos ( $T$ ) e Referenciais (R). Os primeiros constituem tentativas do Falante de evocar uma propriedade que se aplica a entidades; já os Referenciais são tentativas do Falante de evocar um referente, ou seja, um conjunto (nulo, único ou múltiplo) de entidades.

Os Atos Discursivos podem ser de diferentes tipos. O primeiro, o Ato Expressivo, emite uma expressão direta aos sentimentos do Falante, como em Droga!. O segundo tipo, Ato Interativo, ocorre quando um Falante executa uma ação comunicativa, mas a expressão é fática, ou seja, a expressão linguística serve como uma função social ou do discurso, 
mas nenhum conteúdo é transferido (KEIZER, 2015). Tais declarações consistem em expressões personalizadas e invariáveis que geralmente ocorrem no início ou no final de uma construção, como Parabéns! ou Obrigado! (HENGEVELD; MACKENZIE, 2008, p. 77). 0 terceiro tipo, Ato llocutivo, envolve um Conteúdo Comunicado e uma ilocução lexical ou abstrata $\left(F_{1}\right)$, como em Prometo que estarei lá amanhã.

Nesse Nível, as unidades em cada camada podem ter uma função pragmática ou retórica. A função retórica está relacionada em como os Falantes moldam suas mensagens para influenciar seus Ouvintes. Elas ocorrem entre Atos de estatuto diferente, um Nuclear e outro Subsidiário. Para Hengeveld e Mackenzie (2008, p. 53), um Ato Subsidiário pode ter diversas funções retóricas, as quais podem ser Motivação, Orientação, Correção, Aposição e Concessão.

O Nível Representacional se relaciona aos aspectos semânticos da unidade linguística. Neste domínio, as estruturas linguísticas são descritas em termos da denotação que fazem de uma entidade e, portanto, a diferença entre as unidades desse nível é feita em termos da categoria denotada.

O Conteúdo Proposicional é a camada mais alta do Nível Representacional e exprime um constructo mental, marca um desejo ou até mesmo uma crença do Falante. Organizados de forma hierárquica, os Conteúdos Proposicionais (p) apresentam Episódios (ep).

Os Episódios podem ser constituídos por um ou mais Estado-de-Coisas. Estados-deCoisas são entidades localizadas no espaço e no tempo, que podem ser reais ou não reais. Segundo Keizer (2015), cada Estado-de-Coisas é caracterizado por uma Propriedade (ou seja, um predicado), um ou mais Indivíduos (x) e, em razão de sua adequação tipológica, Hengeveld e Mackenzie (2008) reconhecem também as categorias de Lugar, Tempo, Modo, Quantidade e Razão.

O Nível Morfossintático trata da Codificação do que é expresso no Nível Interpessoal e no Nível Representacional. Sua função é receber o input dos dois níveis e compor uma única representação estrutural. As camadas pertencentes a esse nível são: Expressão Linguística (Le), Oração (Cl), Sintagmas (Xp) e Palavras (Xw).

As Expressões Linguísticas (Le) formam a camada mais alta no Nível Morfossintático e consistem em várias unidades morfossintáticas de cada camada inferior (como a Oração, os Sintagmas ou as Palavras), mas também podem conter apenas uma dessas unidades, desde que possam ser usadas de forma independente.

A segunda camada do Nível Morfossintático é a Oração, que é composta por uma combinação de Palavras (Xw), Sintagmas (Xp) e outras Orações, que podem ocorrer mais de uma vez em uma única Oração. 
A terceira camada é formada a partir da combinação sequenciada de Palavras (Xw), Sintagmas (Xp) e Orações incorporadas, todas as quais podem ocorrer mais de uma vez. Por fim, a última camada é a Palavra (Xw), que pode ser simples (consistindo de um único morfema) ou complexa (composta por mais de um morfema).

Dentro deste nível, temos os diferentes processos que podem ocorrer entre as unidades que compõem a Expressão Linguística, os quais podem ser de equiordenação, cossubordinação e coordenação, como mostram os exemplos de Hengeveld e Mackenzie (2008, p. 308) a seguir de (3) a (5):

3. The disciple is as the teacher.

[O discípulo é como o professor.]

4; I threw it carefully and it didn't break.

[Eu joguei cuidadosamente e não quebrou.]

5; Celtic won and Rangers lost.

[Os Celtas ganharam e os Rangers perderam.]

O exemplo (3) ilustra a equiordenação, quando nenhum dos elementos pode ser utilizado independentemente. No exemplo (4), ocorre o fenômeno da cossubordinação, em que o primeiro elemento não pode ocorrer por si só e precisa da segunda oração para ter seu sentido completo, no entanto, a segunda oração poderia ocorrer independentemente da primeira. Por fim, em (5) ocorre a coordenação, pois cada unidade pode ocorrer independentemente uma da outra.

Ainda relacionado ao Nível Morfossintático, podemos observar a ordenação de constituintes, na Gramática Discursivo-Funcional, que mapeia as escolhas feitas no Nível Interpessoal e no Representacional. Nessa perspectiva, quatro posições são consideradas: $\mathrm{P}^{\prime}, \mathrm{P}^{2}, \mathrm{P}^{\mathrm{M}}$ e $\mathrm{P}^{\mathrm{F}}$, e a elas podemos acrescentar outras posições, que são relativas, como podemos observar abaixo:

\begin{tabular}{|l|l|l|l|l|l|l|l|l|l|l|l|l|}
\hline $\mathbf{P}^{\mathbf{I}}$ & $\mathrm{P}^{\mathrm{I}+1}$ & $\mathrm{P}^{\mathrm{I}+\mathrm{n}}$ & $\mathrm{P}^{2}$ & $\mathrm{P}^{2+1}$ & $\mathrm{P}^{\mathrm{M}-n}$ & $\mathrm{P}^{\mathrm{M}-1}$ & $\mathbf{P}^{\mathbf{M}}$ & $\mathrm{P}^{\mathrm{M}+1}$ & $\mathrm{P}^{\mathrm{M}+n}$ & $\mathrm{P}^{\mathrm{F}-\mathrm{n}}$ & $\mathrm{P}^{\mathrm{F}-1}$ & $\mathbf{P}^{\mathbf{F}}$ \\
\hline
\end{tabular}

Se considerarmos, no entanto, a camada da Expressão Linguística, temos outra configuração, com duas posições prosodicamente salientes. A primeira, a posição inicial, antecede a Oração (Pre); a segunda, na posição central, está designada para a Oração propriamente dita (Pcentro), que terá suas próprias posições; por fim, a posição final, que segue a Oração ( $\left.P^{p o s}\right)$, como vemos no quadro a seguir: 
Quadro 1. Posição dos constituintes nas camadas da Oração e da Expressão Linguística

\begin{tabular}{|c|c|}
\hline Expressão Linguística & Pre $\mid P^{\text {centro } \mid \text { Pós }}$ \\
\hline Oração & $\left|P^{I} P^{M} P^{F}\right|$ \\
\hline
\end{tabular}

Fonte: adaptado de Pezatti (2014, p. 83)

Como mostra o quadro, a posição central da Expressão Linguística é expandida, abrigando os membros coordenados.

O último Nível proposto pela teoria, o Fonológico, é específico de cada língua e contém a representação fonológica do discurso. Suas camadas, em uma representação hierárquica decrescente, são: Enunciado (U), Sintagma Entonacional (IP), Sintagma Fonológico (PP), Sintagma Fonológico (PW), Pé (F) e Sílaba (S).

\section{Metodologia}

O percurso metodológico adotado para este trabalho, cujos resultados foramapresentados em PEDRO (2020), compreende seis etapas: escolha do corpus, leitura do corpus, coleta dos usos oracionais de pero, classificação das ocorrências em níveis e camadas, identificação dos possíveis processos, e, por último, caracterização morfossintática das orações.

O corpus utilizado para este trabalho foi o PRESEEA (Proyecto para el Estudio Sociolinguístico del Español de España y de América). Por se tratar de um projeto grandioso, que tem como objetivo formar um corpus de língua falada em língua espanhola, compreendendo diversos países, não está completo. Isso justifica nossas escolhas dentro do corpus, delimitando nossa análise nas cidades de Granada e Alcalá de Henares, na Espanha, cidades que apresentam organização já definida dos inquéritos propostos.

\section{Análise dos dados}

Observe a ocorrência (6):

6. E: ¿eres de Alcalá?

I: no, nací en Valencia pero

E: uhum

I: toda la familia de mi madre es de Alcalá. (ALCA_M23_010) 
[E: Você é de Alcalá?

I: não, nasci em Valência mas

E: uhum

\section{I: toda a família da minha mãe é de Alcalá]}

Na ocorrência (6), podemos observar que pero está inserido em uma relação binária, pois segue o esquema $A$ pero $B$, em que os elementos envolvidos na relação, $A$ e $B$, são nací en Valencia e toda la família de mi madre es de Alcalá. Esses elementos não são contraditórios por si só, mas são colocados como contrastivos pelo falante a partir de seu conhecimento e de suas pressuposições, advindos do Componente Contextual. Assim, a relação de contraste em nací en Valencia e toda la família de mim madre es de Alcalá se dá porque o falante está em situação de entrevista e sabia previamente da necessidade do entrevistador de ter informantes da cidade de Alcalá de Henares.

O Falante, ao ser questionado sobre sua cidade de origem, reconhece que o fato de ele ter nascido em Valencia (e não em Alcalá de Henares) poderia ser interpretado pelo Ouvinte como um possível obstáculo para que ele fosse entrevistado, o que o leva a apresentar uma informação que, para ele, é mais importante, que é o fato de a família de sua mãe ser de Alcalá, pois julga que essa informação poderia satisfazer o entrevistador. Os dois membros envolvidos, portanto, A e B, são colocados pelo Falante como contrastivos. Ele, na verdade, concede, no primeiro membro, A, uma informação, para, em seguida, no segundo membro, B, colocar uma informação que julga comunicativamente mais importante.

Os elementos A e B são unidades de sentido dotadas de Conteúdo Comunicado (aquilo que se deseja comunicar) e de llocução $(F)$, que especifica uma relação entre Falante (S), no caso, o entrevistado, e Ouvinte (A), o entrevistador, o que caracteriza, na GDF, um Ato Discursivo, unidade do Nível Interpessoal. Observa-se, assim, uma relação entre dois elementos, ou dois Atos Discursivos. Essa relação não é de equipolência, mas de dependência, já que ele atribui a um dos Atos o que ele julga mais relevante na interação, o que configura, na GDF, uma função retórica.

O primeiro Ato Discursivo, nací en Valencia, é o Ato Subsidiário, pois nele o Falante coloca o conteúdo menos importante, e o segundo Ato Discursivo, toda la família de mi madre es de Alcalá, o Nuclear, já que o Falante apresenta nele o conteúdo mais relevante para a interação. Nessa relação, o Falante concede, no primeiro Ato, uma informação, para, no segundo, corrigi-la (parcial ou totalmente) e, assim, atualizar seu Ouvinte, o que caracteriza a função retórica Concessão (Conc). Em outras palavras, essa função assinala uma relação desigual entre os Atos Discursivos envolvidos, em que o primeiro Ato, o Subsidiário, apresenta algo que o Falante concede para, a seguir, no segundo Ato, o Nuclear, apresentar o que julga mais importante, como mostra a representação da ocorrência (3) a seguir: 
$\left(6^{\prime}\right)\left(M_{i}:\left[\left(A_{i} \text { - -nací en Valencia- }\left(A_{1}\right)\right)_{\text {conc }}\left(A_{j}\right.\right.\right.$ :-toda la familia de mi madre es de Alcalá$\left.\left.\left.\left.\left(A_{\jmath}\right)\right)\right]\right]\left(M_{1}\right)\right)$

Na representação (6') observamos uma relação desigual entre os dois Atos Discursivos, já que o primeiro, nací en Valencia, é o Ato Discursivo Subsidiário, que veicula a função retórica Concessão (Conc), e o segundo, o Nuclear, argumentativamente mais relevante. Trata-se de uma estratégia usada quando o Falante julga que pode haver falta de clareza com relação à referência de algum componente do Conteúdo Comunicado.

Alguns casos analisados mostram que nem sempre pero relaciona dois Atos Discursivos, mas, sim, porções textuais que se voltam para a interação, como mostra (7) a seguir:

7. I:y al revés también una cosa mediocre como te la vendan bien pues te entra te convencen y o sea el comercial es un trabajo la empresa nuestra se dedica a productos de salud y belleza y y si creen en el comercial si el comercial tiene credibilidad el producto te lo compran

\section{E: pero ¿tú qué artimañas empleas?}

I:Bueno

E: ponme un ejemplo

I: jhombre! yo básicamente no puedo plantear que lo tuyo es lo mejor porque

productos buenos hay de otras de otras firmas también tú primero/ lo primero

expones tus productos y explicas objetivamente por qué son buenos. (GRAN_H22_027)

[l: e ao contrário também se te vendem bem uma coisa medíocre então você entra e te convencem ou seja o comercial é um trabalho nossa empresa se dedica a produtos de saúde e beleza e se acreditam no comercial se o comercial tem credibilidade vão te comprar o produto

\section{E: mas quais estratégias você utiliza?}

I: Bom

E: me dê um exemplo

I: Cara, eu basicamente você não pode pensar que seu produto é melhor porque tem outros produtos bons de outras empresas primeiramente você expõe seus produtos e explica obviamente porque são bons]

Em(7), o informante está comentando, no primeiro turno(I) sobre sua empresa e as vendas. O entrevistador (E), ao observar que o falante não falaria nada mais sobre a empresa, lança uma pergunta, pero ¿tú qué artimanhas empleas?, a fim de estimular o ouvinte a dar continuidade à narrativa sobre um aspecto que havia comentado anteriormente, 
suas estratégias de venda. A contrariedade, como se observa, se estabelece no âmbito interacional, pois a pergunta do entrevistador estimula uma reação por parte do ouvinte e impulsiona o discurso. Na Gramática Discursivo-Funcional, esses casos caracterizam Movimentos, camada mais alta do Nível Interpessoal, definidos como uma "contribuição autônoma para uma interação em andamento" (HENGEVELD; MACKENZIE, 2008, p. 50, tradução nossa $\left.{ }^{3}\right)$.

Os Movimentos podem ser constituídos por um único ou por mais Atos Discursivos. Em (7), o Movimento ¿tú qué artimañas empleas? É constituído por um único Ato com llocução interrogativa, conforme mostra a representação em ( $\left.7^{\prime}\right)$

$$
\text { 7'. (M: [( } \left.\left.A_{i} \text { :-qué artimañas empleas- }\left(A_{1}\right)\right]\right)
$$

Em ( $\left(7^{\prime}\right)$, como se observa, pero não faz parte do Ato Discursivo que constitui o Movimento, ele apenas abre o Movimento. De acordo com Hengeveld e Mackenzie (2008), but, equivalente a pero, pode atuar em contextos narrativos quando atua como um elemento que possibilita o Falante fazer algumas digressões sobre o que está sendo narrado, a fim de inserir informações secundárias. Esse papel caracteriza pero como um push marker, um operador que introduz uma unidade que tem por finalidade apresentar um novo assunto na conversação.

Os dados mostram, em poucas palavras, que a atuação de pero se dá basicamente em duas camadas do Nível Interpessoal, Movimento ou Ato Discursivo.

Essas unidades correspondem, segundo os princípios do alinhamento, a outras unidades do Nível Representacional, como mostra (8) a seguir.

8. ahora ya hay oficinas eeh por todos los sitios y bancos pero hasta hace hasta hace unos años el centro era el cogollito donde estaba todo. (ALCA_H32_033)

[Agora tem escritórios por todos os lugares e bancos mas até uns anos atrás centro era o ponto principal, onde estava tudo.]

Em (8), nota-se que os elementos colocados como contrastivos pelo falante são a ahora ya hay oficinas por todos los sitios e hasta hace unos años el centro era el cogollito donde estaba todo são unidades de sentido dotadas de llocução, Conteúdo Comunicado, Falante e Ouvinte, o que caracteriza, na Gramática Discursivo-Funcional, um Ato Discursivo, camada do Nível Interpessoal.

3 No original: "[...] an autonomous contribution to an ongoing interaction.". 
Na perspectiva da Gramática Discursivo-Funcional, esses elementos configuram dois Conteúdos Proposicionais, a camada mais alta do Nível Representacional. Os Conteúdos Proposicionais são compostos por Episódios, formados, por sua vez, por Estados-deCoisas.

Em (8), o falante descreve como é a distribuição dos escritórios atualmente e compara com a situação deles de alguns anos atrás, quando somente o centro continha escritórios e comércio. Os elementos utilizados para estabelecer o contraste são ahora (agora) e hace unos años (faz alguns anos), ou seja, são marcas de tempo relativo que caracterizam os dois Estados-de-Coisas respectivamente, que compõem Conteúdos Proposicionais (p), como mostra a representação a seguir:

8'. ( $p_{1}$ : - ahora ya hay oficinas por todos los sitios- $\left.\left(p_{\mid}\right)\right)\left(p_{j}\right.$ : - hasta hace unos años el centro era el cogollito donde estaba todo- $\left.\left(p_{\mathrm{J}}\right)\right)$

Como se observa, a constituição das relações com pero é diferente em cada nível. Para melhor visualização do alinhamento entre os Níveis Interpessoal e Representacional, veja as respectivas representações a seguir da ocorrência anterior em (8") e (8"').

8". NI: $\left(M_{1}:\left[\left(A_{i} \text { - - ahora ya hay oficinas por todos los sitios- - }\left(A_{1}\right)\right)_{\text {conc }}\left(A_{j}:-\right.\right.\right.$ hasta hace unos años el centro era el cogollito donde estaba todo- $\left.\left.\left.\left(A_{\jmath}\right)\right)\right]\left(M_{j}\right)\right)$

8'”. NR: ( $p_{1}$ : - ahora ya hay oficinas por todos los sitios- - $\left.\left(p_{1}\right)\right)\left(p_{j}\right.$ : - hasta hace unos años el centro era el cogollito donde estaba todo- $\left.\left(p_{\mathrm{J}}\right)\right)$

Tendo visto o alinhamento entre os Níveis Interpessoal e Representacional, passamos agora a tratar do Nível Morfossintático. Como mencionado anteriormente, o propósito do Nível Morfossintático é tomar o input dos Níveis Interpessoal e Representacional e criar uma representação estrutural que será convertida em um constructo fonológico no Nível Fonológico, que, finalmente será input para o Componente de Saída. Vejamos a ocorrência (9) a seguir:

9. es un águila pero es un vago. $(018, \mathrm{M}, \mathrm{AH}, 54, \mathrm{~S})$

[é muito inteligente, mas é um preguiçoso]

Observamos que os elementos relacionados por pero, es un águila e es un vago, configuram Orações, conjunto sequenciado de Palavras que se estrutura em torno de um verbo. Nesse sentido, há dois elementos, que configuram Atos Discursivos de estatuto desigual no Nível Interpessoal e que são codificados por Orações no Nível Morfossintático. Essa diferença de estatuto se reflete no processo de codificação, em que a Palavra Gramatical (Gw) pero garante que o ouvinte interprete o segundo Ato como comunicativamente mais relevante. 
Em (9), temos uma relação independente entre os elementos es un águila e es un vago, o que caracteriza, na GDF, o processo da coordenação. Veja que essas unidades não dependem uma da outra, ou seja, podem ser usadas independentemente: es un águila e es un vago.

Como se observa, as duas Orações, $\left(\mathrm{Cl}_{1}\right)$ e $\left(\mathrm{Cl}_{\mathfrak{J}}\right)$, que compõem a Expressão Linguística (Le) não apresentam relação de constituência entre elas. O processo da coordenação pode, assim, ser representado como segue:

9'. $\quad\left(\mathrm{Le}_{\mathrm{l}}:\left[\left(\mathrm{Cl}_{\mathrm{l}}\right.\right.\right.$ : - es un águila $\left.(\mathrm{Cl})\right)(\mathrm{Gw}$ pero $(\mathrm{Gw}))\left(\mathrm{Cl}_{\jmath}\right.$ : - es un vago $\left.\left.\left.\left(\mathrm{Cl}_{\jmath}\right)\right)\right](\mathrm{Le})\right)$

No Nível Morfossintático, portanto, as Orações constituem o processo da coordenação, quando os dois elementos são independentes. Quando isso acontece, formam uma única Expressão Linguística. Neste caso, as duas Orações se abrigam na posição Pcentro, que se expande para abrigar as Orações envolvidas, conforme mostra o quadro 2 a seguir:

Quadro 2. Posição das orações coordenadas adversativas

\begin{tabular}{|l|l|l|}
\hline Ppre & Pcentro & Ppos \\
\hline & $\mathrm{O}_{1} \mathrm{e} \mathrm{O}_{2}$ & \\
\hline
\end{tabular}

Fonte: Elaboração própria

A posição central também é ocupada pelas orações introduzidas por pero que configuram um Movimento na GDF, como mostra (10) a seguir, já apresentado em (7), mas repetido aqui por conveniência:

\section{Pcentro}

10. Pero ¿tú qué artimañas empleas? (GRAN_H13)

[mas quais estratégias você utiliza?]

$\mathrm{O}_{1}$

No Nível Morfossintático, portanto, as orações introduzidas por pero configuram o processo de coordenação na camada da Expressão Linguística, em que as duas Orações podem ser utilizadas independentemente. 


\section{Considerações finais}

O termo alinhamento é utilizado por Hengeveld e Mackenzie (2009) para referir-se ao mapeamento de unidades pragmáticas e semânticas em unidades morfossintáticas. No que concerne ao alinhamento entre os níveis nas orações introduzidas por pero, nossas análises mostram o alinhamento entre as camadas do Nível Interpessoal, do Nível Representacional e do Nível Morfossintático.

As orações com pero constituem função retórica Concessão, pois trata-se de uma estratégia de que dispõe o falante para alcançar seus objetivos comunicativos.

A camada de atuação das orações com pero é basicamente a do Ato Discursivo. Na camada do Ato Discursivo, pero atua em relações binárias, sendo o primeiro Ato Subsidiário e o outro, Nuclear. No Ato Nuclear, é apresentada a informação que o falante julga comunicativamente mais relevante, e no Ato Subsidiário, a informação que considera menos relevante do ponto de vista comunicativo.

Os dados revelam também casos de Movimento, que são compostos por um ou mais Atos Discursivos, o que nos permite dizer que a camada de constituência dessa relação é a do Ato Discursivo. No Nível Representacional, por sua vez, a camada de constituência dos elementos por excelência é o Conteúdo Proposicional, já que os elementos não são contrastantes por si só, mas baseiam-se em crenças e percepções, ou seja, construtos mentais do falante, o que caracteriza a camada do Conteúdo Proposicional. No Nível Morfossintático, por fim, esses elementos se constituem na camada da Oração, um conjunto sequenciado de Sintagmas e, possivelmente, uma Palavra gramatical, conforme sintetiza o Quadro 3:

Quadro 3. Alinhamento entre os níveis

\begin{tabular}{|l|l|}
\hline Nível & Camada \\
\hline Interpessoal & Ato Discursivo \\
\hline Representacional & Conteúdo Proposicional \\
\hline Morfossintático & Oração \\
\hline
\end{tabular}

Fonte: Elaboração própria

O alinhamento das estruturas oracionais introduzidas por pero no espanhol mostra que elas ocorrem nas camadas mais altas de cada nível, o que comprova o estatuto interpessoal dos elementos introduzidos por esse juntor, os quais se voltam ora para a interação, ora para o monitoramento do discurso. 


\section{Agradecimentos}

O presente trabalho foi realizado com apoio da Coordenação de Aperfeiçoamento de Pessoal de Nível Superior - Brasil (CAPES) - Código de Financiamento 001, processo no 88887.191045/2018-00.

\section{REFERÊNCIAS}

DIK, S. C. The theory of functional grammar. Pt I: The structure of the clause. New York: Mounton de Gruyter, 1997.

FLAMENCO GARCÍA, L. Las construcciones concesivas y adversativas. In: BOSQUE, I.; DEMONTE, V. (org.). Gramática descriptiva de la lengua española. Madrid: Espasa-Calpe, 1999. p. 3805-3878. v. 3: Entre la oración y el discurso.

GILI GAYA, S. Curso superior de sintaxis española. Barcelona: Vox, 2002.

HENGEVELD, K.; MACKENZIE, L. Functional Discourse Grammar: a typologically-based theory of language structure. Oxford: University Press, 2008.

HENGEVELD, K.; MACKENZIE, L. Alinhamento interpessoal, representacional e morfossintático na Gramática Discursivo-Funcional. DELTA, São Paulo, v. 25, n. 1, p. 181-208, 2009. Disponível em: vhttp://www.scielo.br/scielo.php?script=sci_ arttext\&pid=S010244502009000100007\&lng=en\&nrm=iso. Acesso em: 2 out. 2009. DOI: https://doi.org/10.1590/S0102-44502009000100007

KEIZER, E. A functional Discourse Grammar for English. Oxford: University Press, 2015.

PEDRO, C. C. As orações com 'pero' no espanhol peninsular falado sob perspectiva da Gramática Discursivo-Funcional. 2020. Dissertação (Mestrado em Estudos Linguísticos) - Instituto de Biociências, Letras e Ciências Exatas, Universidade Estadual Paulista, São José do Rio Preto, 2020.

PRESEEA. Corpus del Proyecto para el estudio sociolingüístico del español de España y de América. Alcalá de Henares: Universidad de Alcalá, 2014a. Disponível em: http://preseea. linguas.net. Acesso em: 29 dez. 2019.

PRESEEA. Corpus del Proyecto para el estudio sociolingüístico del español de España y de América. Granada: Universidad de Granada, 2014b. Disponível em: http://preseea. linguas.net. Acesso em: 29 dez. 2019.

REAL ACADEMIA ESPAÑOLA Y ASOCIACIÓN DE ACADEMIAS DE LA LENGUA ESPAÑOLA. Nueva gramática de la lengua española: morfología y sintaxis. Madrid: Espasa, 2009. 